\title{
REVIEW
}

Ann R Coll Surg Engl 2008; 90: 633-637

doi $10.1308 / 003588408 \times 321611$

\section{Pelvic fasciae in urology}

\section{B RAYCHAUDHURI, D CAHILL}

\section{Department of Urology, Guy's Hospital, London, UK}

ABSTRACT

INTRODUCTION Despite the vast literature on pelvic fascia, there is confusion over the periprostatic structures and their nomenclature, including their orientation, the neurovascular bundles and the existence of the prostatic 'capsule'. In this review, we seek to clarify some of these issues.

MATERIALS AND METHODS Review of published medical literature relating to the anatomy of the pelvic fascia including a Pubmed search using the terms - pelvic fascia, Denonvilliers' fascia, prostate capsule, neurovascular bundle of Walsh, puboprostatic ligament and the detrusor apron.

CONCLUSIONS The findings of the study were as follows:

1. The 'capsule' of the prostate does not exist. Rather, the fibromuscular band surrounding the prostate forms an integral part of the gland.

2. The prostate is surrounded by fascial structures - anteriorly/anterolaterally by the prostatic fascia and posteriorly by the Denonvilliers' fascia. Laterally, the prostatic fascia merges with the endopelvic fascia.

3. The posterior longitudinal fascia of the detrusor comprises a 'posterior layer' of the detrusor apron, extending from the bladder neck to the prostate base.

4. The neurovascular structures tend to be located posterolaterally, but may not always form a bundle. A significant proportion of fibres may lie away from the main nerve structures, along the lateral/posterior aspects of the prostate.

\section{KEYWORDS}

Pelvic fasciae - Nomenclature - Anatomy

\section{CORRESPONDENCE TO}

Declan Cahill, Consultant, Department of Urology, Guy's Hospital, London, UK

E: declan.cahill@gstt.nhs.uk

It is humbling to realise that even today basic anatomy may not be known or all understood.

Patrick C Walsh, 1998

The pelvic fasciae consist of two components: (i) the endopelvic fascia, which primarily covers the pelvic muscles; and (ii) the visceral fascia which covers the pelvic organs and the supplying vessels and nerves. ${ }^{1-5}$ Together, they support and define the structures in the pelvis.

\section{Endopelvic fascia (parietal pelvic/superior pelvic/lateral pelvic/levator fascia)}

Despite the profusion of names (Table 1), the endopelvic fascia is well recognised in the urological literature and its description is fairly standardised. It consists of a sheet of fascia that lines the walls and floor of the pelvis. ${ }^{1,2,4}$ It covers the obturator internus, piriformis, levator ani and coccygeus muscles and is continuous with the transversalis fascia. It is fused to the periosteum of the hipbones. On descending into the troughs that flank the bladder, it forms a white line of fascial condensation, termed the 'fascial tendinous arch' of the pelvis by Myers, ${ }^{1}$ although the prominence of this line may be variable. Fascia that sweeps up medially from this condensed structure is termed the 'visceral pelvic fascia'.
Most neurovascular structures leaving the pelvis lie on the outer side of the pelvic fascia. Conversely, structures on the inner side of the fascia are usually destined for the pelvis. ${ }^{4}$

\section{Visceral pelvic fascia/visceral endopelvic fascia}

The visceral pelvic fascia is a condensation of connective tissue that arises from the parietal fascia laterally. ${ }^{4}$ It provides an investing capsule for the pelvic organs, and also the perineural and perivascular sheaths. Anteriorly, it is attached to the posterior surface of the pubis, and posteriorly to the ischial spine.

\section{Fascia around the prostate}

The nomenclature of the fascial structures around the prostate is not well standardised. Tewari et al. ${ }^{6}$ describe two layers of the periprostatic fascia - the inner layer around the prostate being termed the 'prostatic fascia' while the outer layer is termed the 'lateral pelvic fascia'. However, Kourambas et al. ${ }^{7}$ refer to all tissue between the levator ani and the prostate as the 'lateral pelvic fascia'. For the purpose of this review, however, we used Brook's nomenclature in 


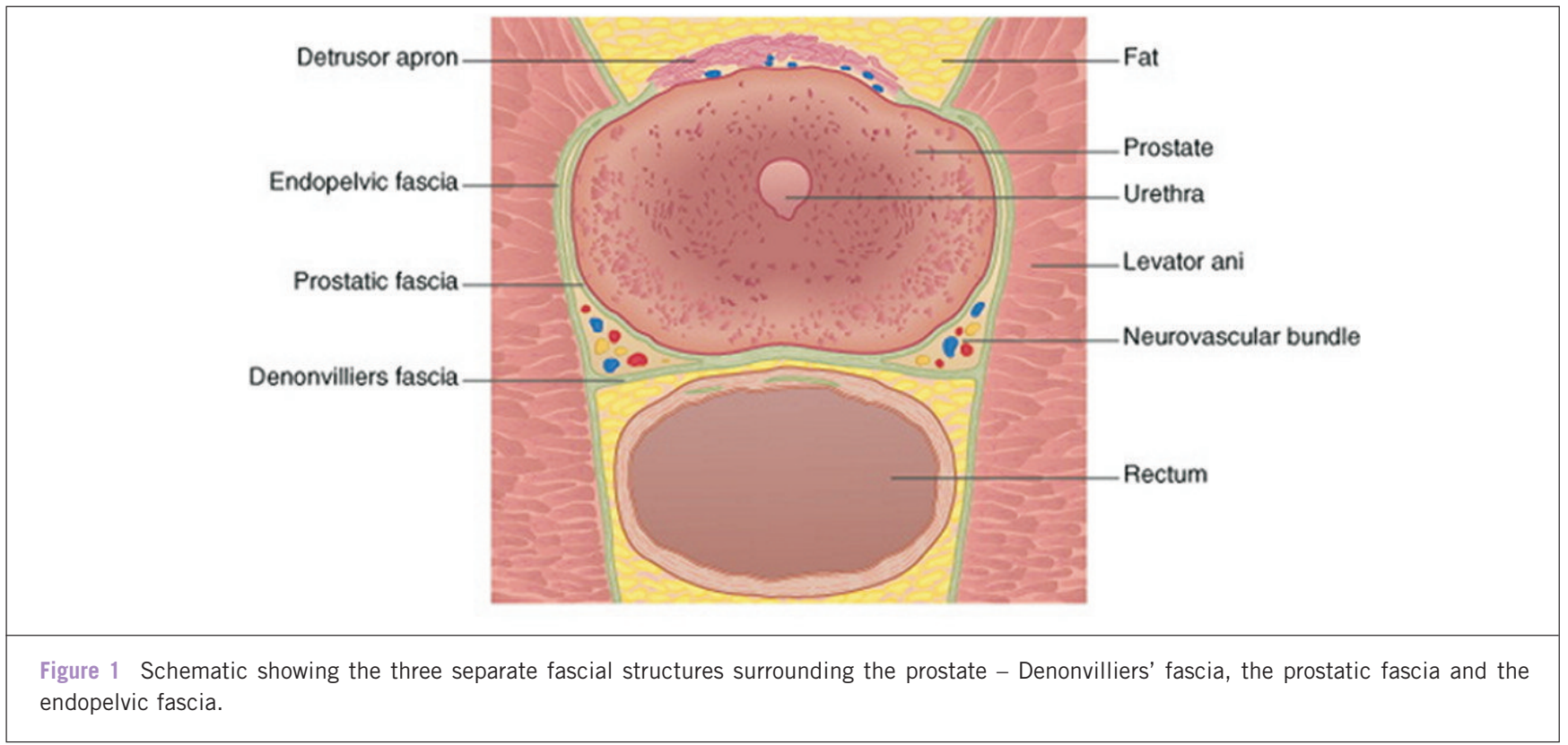

Campbell's Urology, ${ }^{8}$ as that is the most recognised terminology, urologically. Thus, 'endopelvic fascia' refers to the parietal pelvic fascia in the region of the prostate, overlying the levator ani muscle.

Three separate fascial structures surround the prostate: Denonvilliers' fascia, the prostatic fascia and the endopelvic fascia (Fig. 1). ${ }^{5}$ Denonvilliers' fascia lies posteriorly, adher- ent to the prostate, between it and the rectum. It also covers the posterior surface of the seminal vesicles. The prostatic fascia surrounds the prostate gland. Anteriorly and anterolaterally, it is in direct continuity with the fibromuscular stroma of the prostate. ${ }^{5}$ Laterally, it fuses with the endopelvic fascia. Posteriorly, it fuses with, and is indistinguishable from, Denonvilliers' fascia. ${ }^{5,6}$ The prostate

\section{Table 1 Synonyms for pelvic fascial structures}

\begin{tabular}{lll} 
Anatomical structure & Synonyms in literature & Comment \\
\hline Endopelvic fascia & $\begin{array}{l}\text { Lateral pelvic fascia } \\
\text { Superior pelvic fascia } \\
\text { Parietal pelvic fascia } \\
\text { Levator fascia } \\
\text { Outer layer of periprostatic fascia } \\
\text { Parapelvic fascia }\end{array}$ & $\begin{array}{l}\text { Extension of transversalis fascia, covering the pelvic } \\
\text { musculature }\end{array}$ \\
Visceral pelvic fascia & Visceral endopelvic fascia & \\
Prostatic fascia & Inner layer of periprostatic fascia & Fascia immediately surrounding the prostate gland \\
Prostatic capsule & Inner layer of lateral pelvic fascia & anteriorly and laterally \\
Denonvilliers' fascia & - & Does not exist, actually the fibromuscular layer \\
around the prostate glandular structure
\end{tabular}




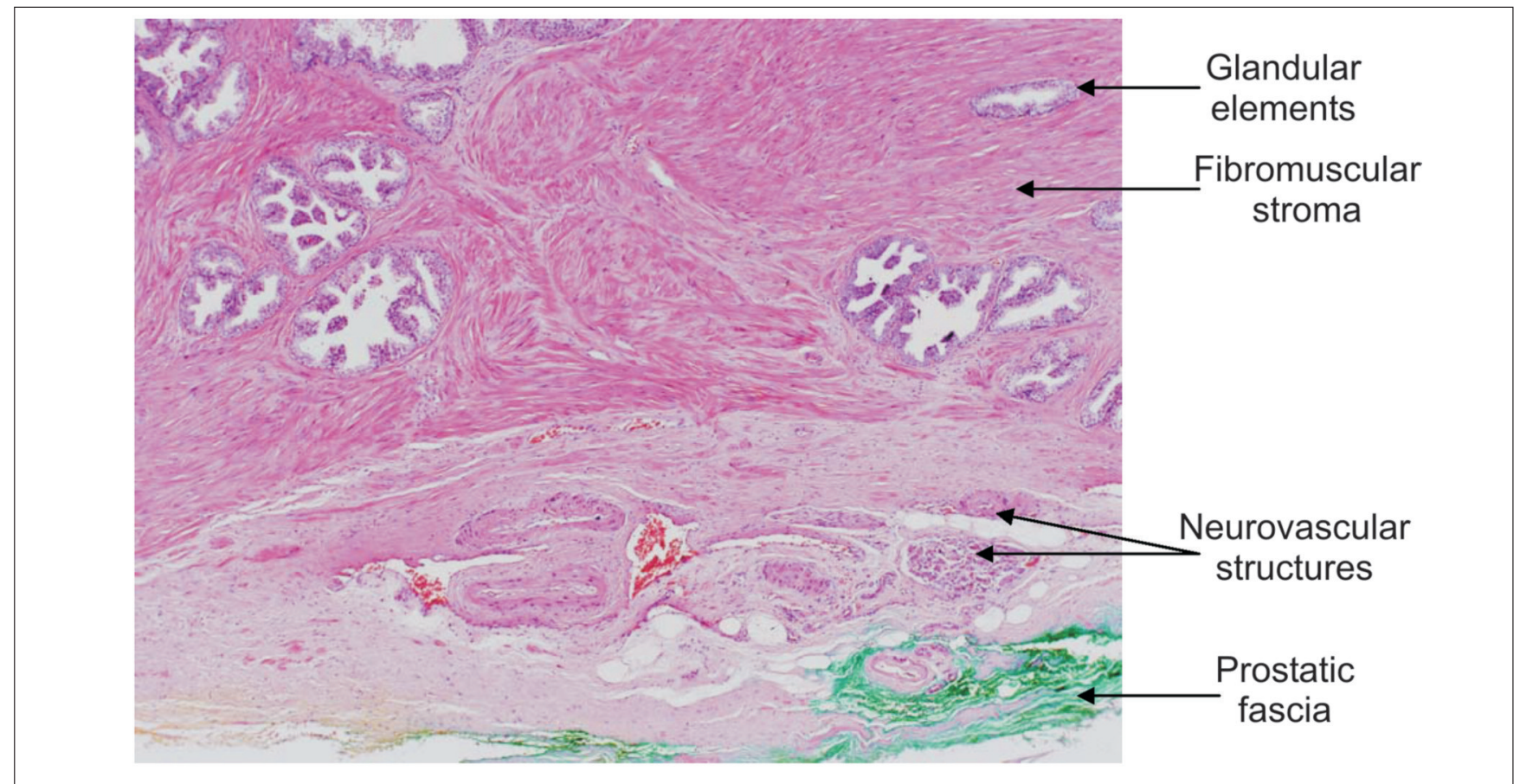

Figure 2 Neurovascular structures around the prostate.

receives its blood supply and autonomic innervation between the layers of endopelvic fascia and the prostatic fascia. ${ }^{5}$ The lateral pelvic fascia has already been described previously.

\section{Prostatic capsule}

The terminology of the prostatic capsule is confusing. Gray's Anatomy ${ }^{9}$ suggests that the prostate is: 'enclosed by a thin, but strong fibrous capsule ... (which) is firmly adherent to the gland and is continuous with a median septum and with numerous fibromuscular septa'. Brooks ${ }^{8}$ describes the capsule as being composed of collagen, elastin and abundant smooth muscle, which fuses with Denonvilliers' fascia posteriorly and the visceral endopelvic fascia (prostatic fascia) anteriorly.

Ayala et al.. ${ }^{9}$ in 1989, suggested that the fibromuscular stroma of the gland does not constitute a true capsule as it is incomplete, especially anteriorly at the apex, and forms an intrinsic and inseparable part of the prostate gland. Sattar et al., ${ }^{10}$ in their morphometric study of 10 radical prostatectomy specimens, suggest that the so-called 'capsule' is a fibromuscular band which shows great homogeneity in its muscle content and muscle density with the prostate stroma. They thus consider it to be simply an extension of the prostatic parenchyma. Lollo et al. ${ }^{11}$ suggest that the space between the prostate, seminal vesicles and the urinary bladder appears to be filled with loose connective tissue, which is continuous from one organ to the next, without interruption by any capsule. They, therefore, conclude that it is difficult to describe a true prostatic capsule as an independent structure on the basis of their study. Young et al.,$^{12}$ in a comparative study of histological and ultrasonic appearances of the prostate, suggest that despite the finding of a regular, 'well-defined' ultrasonic capsule, the histological capsule was frequently either absent or correlated very poorly.

Thus, the wealth of information currently suggests that the 'capsule' of the prostate does not exist. Rather, the prostate is surrounded by a fibromuscular band which, although incomplete anteriorly, is an intrinsic part of the gland, and is adherent to the pelvic connective tissue in regions.

\section{Denonvilliers' fascia/rectovesical septum/prostatorectal fascia/rectogenital fascia}

The plane between wind and water

R. Ger, $1988^{4}$

The embryological origin of this fascia is controversial. Although conventionally thought to develop by obliteration of the rectovesical peritoneal pouch, ${ }^{4,13}$ some studies indicate that it may actually represent a condensation of mesenchymal tissue. ${ }^{14-21}$ Surgically, however, the controversy regarding its structure is more relevant. Although initially described by Denonvilliers as having a single layer, there are a plethora of references in the literature to an 'anterior' and 'posterior' layer, relating to its origin by fusion of the two layers of the 
rectovesical peritoneal pouch. The situation was perhaps best clarified by Tobin and Benjamin in $1945,{ }^{22}$ who said that the socalled posterior layer of the Denonvilliers' fascia was actually the fascia propria of the rectum and, therefore, technically not a part of this structure.

Denonvilliers' fascia forms an important barrier to the spread of prostatic and rectal malignancy. ${ }^{1,23}$ It is generally more adherent to the prostate, except in disease states. Laterally, its limits are variable, depending on where it meets the neurovascular bundle. Kiyoshima et al. ${ }^{24}$ have shown that, medially, the fascia fuses with the fibromuscular stroma of the prostate, while laterally it is separated from the stroma, with the intervening space being filled with adipose tissue. Kourambas et al. ${ }^{7}$ showed that this tissue has no defined lateral edge; rather, it widens and becomes continuous with the extensions of the endopelvic fascia. Anteriorly, it fuses with the prostatic fascia, while posteriorly it fuses with the pararectal fascia. Superiorly, it covers the posterior surface of the seminal vesicles. ${ }^{5}$ Thus, the confluence of the endopelvic fascia, pararectal fascia and the Denonvilliers' fascia forms an 'H'-shaped configuration around the prostate and rectum (Fig. 1). The neurovascular structures tend to be located around this confluence. The fascia is most prominent and dense near the base of the prostate and the seminal vesicles, and thins dramatically near its termination at the striated muscle sphincter. ${ }^{5}$

\section{Neurovascular bundles of Walsh}

Classically, the neurovascular bundles are said to lie posterolaterally on either side of the prostate, enclosed in a fascial sheath and accompanied by the prostatic vessels. As these nerves are usually not visible on gross inspection at surgery, the vessels serve as a surgical landmark for their location. All along the course of the bundles, 'micropedicles' comprised of tiny arteries, veins and nerves, supply the adjacent prostate, thus tethering the bundles posterolaterally. ${ }^{1,6}$

Current literature suggests, however, that true bundle formation does not take place in all cases, although large vessels and nerves do tend to be located at the posterolateral region (Figs 1 and 2). Kiyoshima et al. ${ }^{24}$ found that when the fibromuscular stroma and the lateral pelvic fascia were adherent laterally, the neurovascular bundle tended to be localised, with true bundle formation in the posterolateral region. On the other hand, whenever these two structures remained separated laterally, the 'bundle' tended to be dispersed, without any special localisation. Myers ${ }^{1}$ has also reported a crescentic distribution of the bundle components around the posterolateral aspect of the prostate. Tewari $e t$ $a l .{ }^{6}$ noted that, in addition to the main nerve bundle, there are several smaller nerves, which ramify in the prostatic and Denonvilliers' fascia. Kourambas et $a l .^{7}$ stated that the neurovascular bundles are actually a diffuse collection of structures that are not just confined to the lateral edges of
Denonvilliers' fascia, but also extend medially to the midline, albeit with a gradually decreasing incidence of nerve fibres.

The current consensus of opinion, therefore, is that the neurovascular structures are located in the posterolateral region of the prostate, at the confluence of Denonvilliers' fascia with the endopelvic and pararectal fascia.

\section{Detrusor apron and the puboprostatic ligaments}

The detrusor apron of Myers ${ }^{1,25}$ is an extension of the longitudinal smooth muscle of the bladder (detrusor) anteriorly, in front of the anterior commissure (isthmus) of the prostate. It consists of a loose conglomeration of longitudinal smooth muscle bands and veins. Its thickness is greatest at the bladder neck in the mid-line. Laterally, it fuses with the fascial tendinous arch of the pelvis. It represents a direct continuity of the anterior wall of the bladder with the pubis, via the puboprostatic ligaments, similar to that in the female. ${ }^{25}$

The puboprostatic/pubovesical ligaments arise from the postero-inferior surface of the pubis and pass posteriorly to attach to the prostate in the male. The dorsal vein of the penis/clitoris passes between them. These ligaments contain smooth muscle derived from the bladder, as part of the detrusor apron.

In their paper describing the 'Montsouri' technique of laparoscopic radical prostatectomy, Guillonneau and Vallancien ${ }^{26}$ describe the presence of a fascial structure with sagittal (cephalocaudal) striations, which needs to be incised horizontally, during the posterior bladder neck dissection. They have termed this the 'anterior layer of Denonvilliers' fascia'. Anatomically, however, we know that Denonvilliers' fascia does not extend into the region between the bladder and seminal vesicles. ${ }^{5}$ Recently, Secin et $a l .{ }^{27}$ have proposed that the longitudinal muscle fibres identified during the posterior bladder neck dissection in laparoscopic radical prostatectomy actually represents the posterior longitudinal fascia of the detrusor muscle, externally upholstered by the fibradipose tissue of the bladder adventitia. It extends from the bladder neck to the base of the prostate. This structure could, therefore, be described as a 'posterior layer' of the detrusor apron. It is clearly not the 'anterior layer of Denonvilliers' fascia' incorrectly referred to in the current laparoscopic literature. ${ }^{26}$

\section{Conclusions}

1. The 'capsule' of the prostate does not exist. Rather, the fibromuscular band surrounding the prostate forms an integral part of the gland.

2. The prostate is surrounded by fascial structures - anteriorly/anterolaterally by the prostatic fascia and posteriorly by the Denonvilliers' fascia. Laterally, the prostatic fascia merges with the endopelvic fascia. 
3. The posterior longitudinal fascia of the detrusor comprises a 'posterior layer' of the detrusor apron, extending from the bladder neck to the prostate base.

4. The neurovascular structures tend to be located posterolaterally, but may not always form a bundle. A significant proportion of fibres may lie away from the main nerve structures, along the lateral/posterior aspects of the prostate.

\section{References}

1. Myers RP. Practical surgical anatomy for radical prostatectomy. Urol Clin North Am. 2001; 28: 473-90.

2. Church JM, Raudkivi PJ, Hill GL. The surgical anatomy of the rectum - a review with particular relevance to the hazards of rectal mobilization. Int $J$ Colorectal Dis 1987; 2: 158-66.

3. Borley N, Healy J. True pelvis, pelvic floor and perineum. In: Standring S. (ed) Gray's Anatomy, 39th edn. Edinburgh: Elsevier, 2005; 1359-60.

4. Ger R. Surgical anatomy of the pelvis. Surg Clin North Am 1988; 68 : 1201-16.

5. Walsh PC. Anatomic radical retropubic prostatectomy. In: Campbell's Urology, 8th edn, vol 4. Amsterdam: Elsevier Saunders, 2002; 3107-30.

6. Tewari A, Peabody JO, Fischer M, Sarle R, Vallancien G, Delmas V et al. An operative and anatomic study to help in nerve sparing during laparoscopic and robotic radical prostatectomy. Eur Urol 2003; 43: 444-5.

7. Kourambas J, Angus DG, Hosking P, Chou ST. A histological study of Denonvilliers' fascia and its relationship to the neurovascular bundle. Br J Urol 1998; 82: 408-10.

8. Brooks JD. Anatomy of the lower urinary tract and male genitalia. In: Campbell's Urology, 8th edn, vol 1. Amsterdam: Elsevier Saunders, 2002; 41-80.

9. Ayala AG, Ro JY, Babaian R, Troncoso P, Grignon DJ. The prostatic capsule: does it exist? Its importance in the staging and treatment of prostatic carcinoma. Am J Surg Pathol 1989; 13: 21-7.

10. Sattar AA, Noel JC, Vanderhaeghen JJ, Schulman CC, Wespes E. Prostate capsule: computerized morphometric analysis of its components. Urology 1995; 46: $178-81$

11. Lollo SD, Menchi I, Brizzi E, Pacini P, Papucci A, Sgambati E et al. The morphology of the prostatic capsule with particular regard to the posterosuperior region: an anatomical and clinical problem. Surg Radiol Anat 1997; 19: 143-7.

12. Young MP, Jones DR, Griffiths GJ, Peeling WB, Roberts EE, Parkinson MC. Prostatic 'capsule' - a comparative study of histological and ultrasonic appearances. Eur Urol 1993; 24: 479-82.

13. Glass J. Prostate. In: Standring S. (ed) Gray's Anatomy, 39th edn. Edinburgh: Elsevier, 2005; 1301-4.

14. Wesson MB. The development and surgical importance of the rectourethralis muscle and Denonvilliers' fascia. J Urol 1922' 8: 339.

15. Van Ophoven A, Roth $\mathrm{S}$. The anatomy and embryological origins of the fascia of Denonvilliers: a medico-historical debate. J Urol 1997; 157: 3-9.

16. Benoit G, Delmas V, Quillard J, Gillot C, Hureau J. Clivage inter-prostato-rectal: interet du fascia de Denonvilliers. Presse Med 1983; 12: 2693.

17. Benoit G, Delmas V, Gillot C, Hureau J. Anatomical basis of total prostatocystectomy in man. Anat Clin 1984; 5: 213.

18. Benoit G, Delmas V, Quillard J, Gillot C. Interet chirurgical de l'aponevrose de Denonvilliers. Ann Urol 1984; 18: 284.

19. Benoit G, Boccon-Gibod L, Steg A. Anatomical study of total cystoprostatectomy. Eur Urol 1985; 11: 228.

20. Benoit G, Delmas V, Quillard J, Gillot C, Hureau J: L'Aponevrose de Denonvilliers. Soc Anat Paris 1983.

21. Aigner F, Zbar AP, Ludwikowski B, Kreczy A, Kovacs P, Fritsch H. The rectogenital septum: morphology, function, and clinical relevance. Dis Colon Rectum 2004; 47: 131-40.

22. Tobin CE, Benjamin JA. Anatomical and surgical restudy of Denonvilliers' fascia. Surg Gynecol Obstet 1945; 80: 373.

23. Steele RJC. Disorders of the colon and rectum. In: Cuschieri A, Steele RJC, Moosa AR. (eds) Essential Surgical Practice, 4th edn, module 14, 2002; 594.

24. Kiyoshima K, Yokomizo A, Yoshida T, Tomita K, Yonemasu H, Nakamura M et al. Anatomical features of periprostatic tissue and its surroundings: a histological analysis of 79 radical retropubic prostatectomy specimens. Jpn J Clin Oncol 2004; 34: 463-8.

25. Myers RP. Detrusor apron, associated vascular plexus, and avascular plane: relevance to radical retropubic prostatectomy - anatomic and surgical commentary. Urology 2002; 59: 472-9.

26. Guillonneau B, Vallancien G. Laparoscopic radical prostatectomy: the Montsouri's technique. J Urol 2000; 163: 1643-9.

27. Secin FP, Karanikolas N, Gopalan A, Bianco F, Olgac S, Guillonneau B et al. The anterior layer of Denonvilliers' fascia: a common misconception in the laparoscopic prostatectomy literature. J Endourol 2006; 20 (Suppl 1): A224. 